\title{
A DOCÊNCIA, O ENSINO JURÍDICO E OS PRESSUPOSTOS DE CARL ROGERS: ESTUDO DE CASO EM UMA UNIVERSIDADE PRIVADA
}

\author{
TEACHING, THE LEGAL EDUCATION AND CARL ROGERS ASSUMPTIONS: \\ A CASE STUDY IN A PRIVATE UNIVERSITY
}

\author{
${ }^{1}$ Leonardo José Peixoto Leal \\ ${ }^{2}$ Monica Mota Tassigny
}

\section{RESUMO}

Este artigo propõe avaliar, sob uma visão crítica, a docência e o ensino jurídico no Brasil, a partir de Estudo de Caso em uma Universidade Privada de Fortaleza, tendo como parâmetro os pressupostos implícitos de Carl Rogers. Trata-se de tema relevante, tendo em vista as contínuas críticas acerca da baixa qualidade do ensino da ciência jurídica, além do grande número de profissionais formados com dificuldade de ingresso no mercado e, ainda, os elevados índices de reprovação em exame da ordem dos advogados e concursos públicos, existindo hoje uma nova visão da chamada crise do ensino jurídico no Brasil. Segundo Carl Rogers (1972), o principal papel do professor não é o de apenas ensinar, mas de ajudar o discente a aprender. Esta idéia tem se legitimado, internacionalmente, desde a publicação de Relatório da UNESCO (DELORS, 1998), quando se pontuou que aprender a conhecer constitui-se um dos pilares da educação contemporânea. Rogers (1972), na década de 1960, elaborou uma lista com 10 pressupostos implícitos profundamente arraigados entre professores, paradigmas que deveriam ser combatidos pelos docentes. A metodologia utilizada foi bibliográfica e de campo, com abordagem qualitativa, tratando-se de Estudo de Caso, que levou em conta a opinião (tipo survay) de professores da graduação e as experiências do Programa de Monitoria e Grupos de Estudos. Conclui-se que a avaliação crítica é de fundamental importância na formação dos profissionais do direito, pois o ensino jurídico precisa renovarse, a partir de uma prática docente centrada no aprender.

Palavras-chave: Ensino, Pressupostos, Crise

\footnotetext{
${ }^{1}$ Doutorando em Direito na Universidade Federal do Ceará - UFC, Fortaleza - CE (Brasil). Professor da Universidade de Fortaleza - UNIFOR, Fortaleza - CE (Brasil). E-mail: leonardo.jpleal@ yahoo.com.br

2 Doutora em Educação pela Universidade Federal do Ceará - UFC, Fortaleza - CE (Brasil). Professora da Universidade de Fortaleza, UNIFOR (Brasil). E-mail: monica.tass@ gmail.com
} 


\begin{abstract}
This article proposes to evaluate in a critical view of the legal education in Brazil, from Case Study at a private University of Fortaleza. It is important issue, given the continued criticism about the low quality of teaching of legal science in addition to the large number of entry of difficulty with trained professionals in the market and also the high failure rates in the order of examination lawyers and tenders, existing today a new vision called "legal education crisis" in Brazil. According to Carl Rogers (1972), the main role of the teacher is not only to teach but to help the student to learn. This idea has been legitimized internationally since the publication of the UNESCO Report (Delors, 1998), when it pointed out that "learning to know" constitutes one of the pillars of contemporary education. Rogers (1972), in the 1960s, drew up a list of 10 assumptions implicit deeply rooted among teachers, paradigms that should be addressed by teachers The methodology used was literature and documents with a qualitative approach in the case like an argument from Case Study, considering the Master in Law and the experiences of the Monitoring and Group Study Program. It concludes that the critical evaluation is important in the formation of the legal profession, because the legal education needs to renew itself, from a teaching practice centered learning.
\end{abstract}

Keywords: Education, Assumptions, Crisis 


\section{Introdução}

O presente estudo visa avaliar o ensino jurídico, sobretudo, realçando o processo de ensino e aprendizagem em sua capacidade de despertar e fomentar referida visão nos graduandos em Direito. Trata-se de pesquisa relevante diante da inquietação acerca da propalada "queda de qualidade" do ensino jurídico, em parte atribuído a baixa qualidade do ensino nas universidades públicas, concomitante, a expansão do ensino jurídico pelo setor privado, sem que ocorra controle efetivo da qualidade do ensino e com a qualificação dos professores.

Esta investigação, de natureza teórica e empírica, partiu de pesquisa bibliográfica e de campo com o fim desenvolver dois temas principais: 1) Debater o ensino jurídico no país e a existência de uma visão crítica; 2) Destacar a necessidade de revitalização do ensino jurídico e da prática docente, além da necessidade de empreenderem ações concretas desde a graduação, como o estimulo a programas de monitoria e formação de grupos de estudo, para fomentar novas bases ao ensino jurídico. Para esse fim, fez-se um estudo de caso do curso de Direito de uma Instituição de Ensino particular em Fortaleza-CE na graduação e na pós-graduação. Na análise de todos os elementos tem-se como referência os pressupostos extrínsecos e intrínsecos do ensino desenvolvido por Carl Rogers (1972).

Na mesma direção, a qualificação de um professor universitário tem a ver com uma série de prerrogativas que podem ser relacionadas com um conjunto de traços classificados como aptidões, conhecimentos específicos e experiência profissional, dentre outros. Do mesmo modo, para que se possa avaliar adequadamente o desempenho de um professor universitário, torna-se fundamental identificar seus papéis e responsabilidades, fato que não constitui tarefa fácil, pois a profissão apresenta-se em progressivo grau de complexidade em decorrência das exigências educacionais contemporâneas para a formação do profissional do direito.

Há décadas, admite-se que o principal papel de um professor é o de ensinar e, provavelmente, a maioria dos professores concorde com esta idéia. Contudo, conforme as idéia de Carl Rogers (1972), o principal papel do professor não é o de ensinar, de apenas transmitir conteúdos, mas principalmente, o de ajudar o discente a aprender. 
Esta idéia tem se legitimado, internacionalmente, desde a publicação de Relatório da UNESCO (DELORS, 1998), quando se pontuou que "aprender a conhecer" constitui-se um dos pilares da educação contemporânea e, neste particular, a práxis pedagógica do professor universitário deve concentrar-se menos na mera transmissão de saberes codificados e mais na estimulação da capacidade reflexiva dos discentes, no domínio de instrumentos do conhecimento que os ajude a compreender o mundo, a desenvolver suas capacidades profissionais e de reflexão crítica.

Contudo, apesar da constatável evolução científica e tecnológica da sociedade ao longo dos últimos anos, ainda é comum encontrar docentes no Curso de Direito, cujas práticas pedagógicas sejam conservadoras e que trabalham segundo a perspectiva tradicional de mera reprodução do conhecimento no ensino superior. Rogers (1972), ainda na década de 1960, elaborou uma lista com 10 pressupostos implícitos profundamente arraigados nos programas educacionais. A partir das indicações deste autor, indagou-se: como os professores do ensino superior enxergam sua prática docente? Que ações concretas podem ser empreendidas para um ensino jurídico crítico:

Este artigo está organizado do seguinte modo. Em primeiro lugar, é desenvolvida uma abordagem acerca do ensino jurídico, suas características e seus principais problemas; posteriormente, faz-se uma análise sobre a necessidade e possibilidade de existência de uma visão crítica do Direito. Após avalia-se o Programa de Monitoria, com enfoque no caso da de uma Instituição de Ensino Superior particular em Fortaleza. E finalmente são trazidos os pressupostos implícitos de Carl Rogers e a verificação de sua permanência na concepção de professores sobre sua prática docente.

\section{ENSINO JURÍDICO NO BRASIL}

A educação no Brasil ainda apresenta resultados insatisfatórios em todos os seus níveis. Desde o ensino superior até a alfabetização e educação infantil os problemas são enormes e o investimento público não tem sido suficiente. Tanto isto é verdade que uma das maiores bandeiras das recentes manifestações populares é o necessário investimento em educação de qualidade.

Se os problemas da educação básica são muitos, no ensino superior o quadro não tem sido diferente. Com a baixa qualidade do ensino fundamental e médio, o reflexo não 
poderia ser outro. Assim, com a falta de condições e estrutura das universidades públicas a demanda dos estudantes não é atendida e as faculdades particulares acabam por absorver essa "sobra do mercado de ensino superior" (ZABALA, 2012). Dessa forma, há um crescente exponencial no número de alunos em instituições privadas. Tal realidade se repercute também nos programas de fomento do governo como PROUNI e FIES, todos voltados à facilitação do acesso às faculdades particulares pelos cidadãos de baixa renda.

Em relação ao ensino jurídico, Holanda (2007) afirma que desde o surgimento dos cursos de Direito no Brasil, ainda na época do Império, o ensino jurídico sempre foi marcado pela interdisciplinaridade, tendo servido para o desenvolvimento da educação em vários campos, bem como para aperfeiçoamento político do país por intermédio do espírito crítico e reflexivo despertado pelo ensino superior, rompendo com o tradicional ensino eclesiástico-dogmático existente no país.

No entanto, os cursos de direito sofrem com problemas e fragilidades na atualidade, o primeiro ligado à questão estrutural do ensino no país, o segundo relacionado à tradicional visão dogmática do direito, ou seja, um direito acrítico, imposto, limitado pelo ordenamento ou pelos princípios gerais do direito (GARCEZ, 2014).

Em relação ao primeiro problema é necessária uma maior intervenção estatal no sentido de reestruturar a universidade pública, dando-lhe, inclusive, condições de atender um número maior de estudantes. Como também, no sentido de cobrar e fiscalizar uma excelência no ensino ofertado pelas faculdades particulares, tendo em vista a responsabilidade que é a formação profissional uma vez que estes cidadãos atuarão na sociedade em seguida.

A acomodação por parte das faculdades particulares adotando práticas questionáveis como a baixa remuneração dos professores, a contratação da maior parte de seu quadro de horistas, a falta de incentivo ao aperfeiçoamento dos conhecimentos pelo professor, gera uma baixa qualidade de ensino. Os alunos, em contrapartida, estes não exigem um serviço de qualidade, pois o professor é condescendente nos métodos avaliativos.

Os alunos que chegam ao ensino superior com deficiências provenientes dos problemas do ensino médio e, ao invés de se depararem com uma nova realidade, continuam sendo formados pelo mesmo processo inadequado sem o despertar do senso crítico. 
Este contexto ainda é uma realidade em muitas instituições brasileiras, onde a reprodução dos conhecimentos jurídicos segue um modelo arcaico e tradicional, forcado na chamada "dogmática jurídica". Considerando o direito dogmático, o professor limita- se a repassar os "dogmas" existentes em relação ao sistema jurídico, sem o desenvolvimento de contestação ou análise crítica, remetendo esse procedimento, inclusive, ao método de ensino inicialmente rechaçado pelo ensino jurídico.

Se se pode considerar o direito como uma ciência e sendo inerente à ciência o constante questionamento, a constante verificação da teoria e sua relação com a prática, ou seja, sendo o conhecimento científico provisório, mutável como pode haver uma ciência dogmática? Tal classificação - de direito dogmático - é incoerente em todos os aspectos, pois não se pode admitir ciência sem questionamento. Atrelar ao conhecimento jurídico a ideia de dogmática é o mesmo que subtrair caráter científico da ciência jurídica (MACHADO SEGUNDO, 2008).

Constata-se, desse modo, que o ensino jurídico não tem se preocupado em formar cientistas do direito, questionadores, críticos, em fomentar a pesquisa, a discussão e o questionamento. Mas sim, formar um profissional limitado, isto é, especialista na análise dos dogmas que lhes são impostos, uma análise sempre fechada, dentro da lei ou dentro de um sistema pré-concebido sobre o qual não lhe cabe, na condição de mero estudante, contestar ou duvidar.

Diante disso, evidencia-se a questão da necessidade de quebra de paradigmas, da necessidade de ultrapassar a dogmática, na busca pela excelência da aprendizagem. $\mathrm{O}$ ensino jurídico necessita de saídas urgentes para crise na qual está inserido.

A saída dessa crise passa pela formação do professor. Professores de qualidade certamente elevarão o nível do ensino jurídico, atuando como mediadores para alunos eventualmente prejudicados pelas deficiências do ensino fundamental e médio a se adequarem à nova realidade.

Mas, isso só não basta, são necessários também investimentos e regulação eficiente do setor, permitindo-se assim uma remuneração adequada e justa aos profissionais para que eles possam efetivamente se dedicar à atividade docente e para que atuem mais estimulados a desenvolverem um trabalho eficiente e de qualidade.

Ao mesmo tempo, no mundo contemporâneo, a profissão de professor, em qualquer nível de ensino, enfrenta o paradoxo de sofrer com a desvalorização de sua classe, com salários baixos e más condições de trabalho, embora os professores continuem sendo vistos como figura 
central na propagação de conhecimento (FERREIRA; SILVA; SHUVARTZ, 2009). Embora em condições limitadas de trabalho, a sociedade ainda espera grandes contribuições do professor, que ele não seja um mero docente repassador de conteúdos memorizáveis, mas recai sobre ele a expectativa e a responsabilidade de formar profissionais e líderes capacitados para o mercado de trabalho, por meio de metodologias inovadoras e não apenas repassadores de conteúdos arraigadas à cultura tradicional de serem apenas meros reprodutores de conhecimentos (ALMEIDA, 2013).

A colocação acima implica que a educação, vista sob muitos ângulos, também é entendida como mera reprodutora do sistema (BOOURDIEU; PASSERON, 1975). Nestes termos, a educação teria apenas a finalidade de reproduzir o próprio sistema capitalista desigual, e ainda a passividade, o individualismo etc (DEMO, 2008). Nesta perspectiva, a função docente é somente a de repassar conteúdo e ao aluno cabe memorizar esses conhecimentos. E assim, arraigou-se no sistema educacional a cultura da memorização.

Pimenta e Anastasiou (2002) afirmam que na maioria das instituições de ensino superior, ainda predominam o despreparo e a falta de motivação (ou de interesse) dos professores, no que diz respeito ao processo de ensino-aprendizagem pelo qual são responsáveis, mesmo com larga experiência. Desse modo, existe uma preocupação com a não qualificação de profissionais com relação à docência universitária em atuação, mesmo com a crescente exigência do mercado e posicionamento da comunidade universitária sobre essa profissionalização (BARBOSA, 2011).

\section{PERSPECTIVAS DE VISÃO CRÍTICA DO DIREITO}

Destaca-se, em primeiro lugar que uma visão crítica deve ser ferramenta indissociável do ensino jurídico. Tal verificação pode ser evidenciada pelo fato de que os profissionais do Direito, em regra, servirão, na maioria das vezes, atuando no aparato estatal e, além disso, comporão, na essência, os órgãos do Poder Judiciário e do Ministério Público, responsáveis máximos pela interpretação e efetivação do direito por intermédio da aplicação de sanções aos descumprimentos eventualmente existentes.

Ressalta-se que o jurista tem sua atuação em ações desenvolvidas na máquina estatal, sendo muitas vezes difícil atuar, dentro desse contexto, com uma postura 
crítica, sobretudo, se sua formação passou por um ensino desenvolvido de forma acrítico e repetitivo, de característica dogmática. Paulo Freire (1996) destaca que a inquietude e a capacidade crítica são necessidades prementes do ser humano e de todo o processo de ensino.

É no cenário de um ensino apenas descritivo, sem lugar para o debate e a contestação que se pode classificar como nociva uma proposta de aprendizagem dissociada de uma visão crítica. Caso os professores sejam meros reprodutores de conteúdo, estimulando, por consequência, esse comportamento nos alunos, a tendência será o arrefecimento de uma visão crítica no ambiente acadêmico e, logicamente, terá reflexos na área profissional do direito.

A chamada dogmática jurídica, ao defender a existência de categorias definidas e sedimentadas e atemporais de conhecimentos jurídicos, contribui para essa perspectiva do ensino do Direito, o que é incompatível com a verdadeira ciência jurídica como afirma Machado Segundo (2008, p. 40)

\begin{abstract}
Não há, portanto, a "mera descrição" de normas pelo cientista ou pelo aplicador do Direito, sendo descabido falar-se numa "função meramente reprodutiva" da ciência jurídica. Aliás, Miranda Coutinho chega mesmo a admitir decisões não só praeter legem mas também contra legem, firmando serem elas ,a prova cabal de que o texto e a regra não aprisionam o sentido e, portanto, pode ele não estar ex ante ali presente ${ }^{e c}$. Não se trata, note-se, de algo arbitrário. (Destaques do original)
\end{abstract}

Com o fim de contar com professores que fujam da tradição da mera descrição de conteúdo e da dogmática jurídica, estabelecendo verdadeira interlocução com o corpo discente e estimulando uma visão crítica do Direito, torna-se indispensável à existência de um profissional docente bem formado e com capacitação adequada para esse objetivo.

\title{
3. PRESSUPOSTOS DE CARL ROGERS
}

Ainda na década de 1960, quando a docência era marcada por viés extremamente tradicional, Carl Rogers (1902-1987) já estava à frente de seu tempo. As suas idéias no campo da educação são uma extensão da teoria que desenvolveu como psicólogo. Nos dois campos sua contribuição foi muito original, opondo-se às concepções e práticas dominantes nos consultórios e nas escolas.

A terapia rogeriana se define como não-diretiva e centrada no cliente (palavra que Rogers preferia a paciente), porque cabe a ele a responsabilidade pela condução e pelo sucesso do tratamento. Para Rogers, o terapeuta apenas facilita o processo. Em seu ideal de ensino, o 
papel do professor se assemelha ao do terapeuta e o do aluno ao do cliente. Isso quer dizer que a tarefa do professor é facilitar o aprendizado, que o aluno conduz a seu modo.

Segundo Rogers (1972), a tarefa do professor é liberar o caminho para que o estudante aprenda a aprender. Isso quer dizer que a tarefa do professor é facilitar o aprendizado, que o aluno conduz a seu modo. Esta forma de pensar contrastava com o método rígido de ensino de sua época, no qual os professores eram autoridades máximas, dono de saberes inquestionáveis, cujos métodos pedagógicos e avaliativos aferiam a capacidade de memorização dos alunos, os quais eram submetidos a uma série de conteúdos a serem reproduzidos a serem assimilados, decorados e que não tinham direito de contra argumentar ou criticar (MILANESI; AMATUZZI, 2008; ROGERS, 1972).

No campo da educação, Carl Rogers (1972) pouco se preocupou em definir práticas pedagógicas. Além disso, estava convencido de que as pessoas só aprendem aquilo de que necessitam ou o que querem aprender. Sua atenção recaiu sobre a relação aluno-professor, que deve ser impregnada de confiança e destituída de noções de hierarquia. Instituições como avaliação, recompensa e punição estão completamente excluídas, exceto na forma de autoavaliação. Embora anticonvencional, a pedagogia rogeriana não significa abandonar os alunos a si mesmos, mas dar apoio para que caminhem sozinhos na elaboração de novos conhecimentos, no senso crítico e na capacidade de aprender

Rogers (1972) elaborou uma lista com 10 pressupostos implícitos profundamente arraigados nos programas educacionais, considerados tradicionais e antipedagógicos. Foram considerados paradigmas que deviam ser investigados e refutados pelos docentes. A seguir, apresentam-se os pressupostos de Rogers (1972; SOBREIRA, 2014)

Quadro 1 - Pressupostos implícitos de Carl Rogers

\begin{tabular}{|cl|}
\hline \multicolumn{1}{|c|}{ Pressupostos Implícitos } \\
\hline 1. & Não se pode confiar que o estudante busque sua própria aprendizagem científica e profissional. \\
\hline 2. & A capacidade para passar nos exames é o melhor critério de seleção do aluno e de julgamento da \\
& vocação profissional. \\
\hline 3. & Avaliação é educação, educação é avaliação. \\
\hline 4. & Exposição de matéria é igual a aprendizagem: o que é dado, na lição, é o que o aluno aprende. \\
\hline 5. & Conhecimento é a acumulação, pedra sobre pedra, de conteúdo e de informação. \\
\hline 6. & Conhecem-se verdades em Psicologia. \\
\hline 7. & Método é ciência. \\
\hline 8. & Aprendizes passivos podem tornar-se cientistas criativos. \\
\hline 9. & "Depurar" a maioria dos alunos é método satisfatório de produzir cientistas e clínicos. \\
\hline 10. & Os alunos são mais bem considerados como objetos manipuláveis, não como pessoas. \\
\hline
\end{tabular}

Revista de Pesquisa e Educação Jurídica | e-ISSN: 2525-9636 | Minas Gerais | v. 1 | n. 2 | p. 154 - 171 | Jul/Dez. 2015. 
Fonte: ROGERS (1972).

Rogers entendia que não se podia inculcar diretamente em outrem um saber ou uma conduta. $\mathrm{O}$ que se pode facilitar é sua aprendizagem. Também entendia que a atitude dos professores no processo de ensino-aprendizagem refletia a própria educação deles, estando presos em um meio cujo processo educativo é tido com algo pronto, cabendo- lhes o papel de transmissores de conhecimento, com conteúdo engessado, assim como lhes foi passado (MILANESI; AMATUZZI, 2008; ZIMRING, 2010).

A verdadeira aprendizagem ocorre quando o discente conhece bem como ele funciona, o que consiste em colocá0lo sempre disposto a novas aprendizagens. O formador (porfessor) deve assim contribuir para a clarificação pessoal e grupal dos objetivos de aprendizem. (ZIMRING, 2010) Rogers (1972) disse que a liberdade era imprescindível à aprendizagem 67 significativa, pois permitia e incentivava a liberdade de expressão, a escuta dos alunos, educando-os com suas próprias experiências, sem medo dos conflitos e das contradições existentes. Esse clima de liberdade oferecido pelo formador/professor proporciona a humanização da educação, o envolvimento do aluno em uma aprendizagem mais significativa

Considerava que a aprendizagem verdadeira não ocorre a não ser que os alunos trabalhem em problemas, questões e dúvidas que são reais para ele, sendo o professor figura central nesse processo, atuando como facilitador. Deve assim se esforçar para organizar um conjunto de recursos colocados à disposição do grupo para que as aprendizagens significativas ocorram (ZIMRING, 2010)

Para o alcance desse objetivo desenvolveu-se uma pesquisa bibliográfica e de campo do tipo survay (de opinião) com coleta de dados a partir da aplicação de questionário em um período de período de 5 meses: agosto, setembro, outubro, novembro e dezembro de 2014. O objetivo era identificar como os professores de ensino superior de uma Universidade Privada via sua prática docente na atualidade, tendo como parâmetro os pressupostos implícitos de Rogers.

Foi realizada uma pesquisa exploratória, por meio de um questionário semiestruturado, com 10 questões, que se voltavam a identificar o quanto os professores de ensino superior de modo geral acreditavam, segundo sua percepção, em cada um dos pressupostos implícitos de Carl Rogers (SOBREIRA, 2014). 
Ressalta-se que a presente pesquisa já foi aplicada primeiramente por Sobreira (2013) entre professores do curso de administração de uma faculdade privada. Seguindo a orientação desta pesquisadora o questionário foi adaptado para Instituições de Ensino Superior de Direito. Assim como o questionário aplicado por Sobreira (2013), o texto de dois pressupostos foram modificados, mas sem perder seu sentido original, sendo eles: "Conhecem-se verdades em

Psicologia" (retirou-se a parte "em psicologia" e substituiu- se por "nas disciplinas do ensino superior”) e “"Depurar' a maioria dos alunos é método satisfatório de produzir cientistas e clínicos" (substitui-se por "Um curso difícil e exigente, onde somente os melhores alunos conseguem concluir, é um método satisfatório de produzir os melhores cientistas e profissionais"). Essas adaptações foram feitas para que a pesquisa pudesse contemplar qualquer curso e que todos os itens fossem de fácil entendimento pelos respondentes.

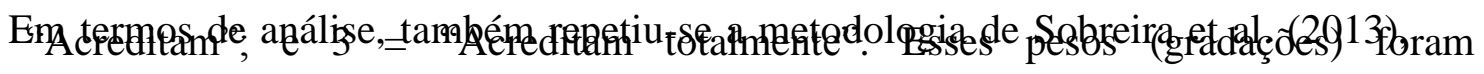

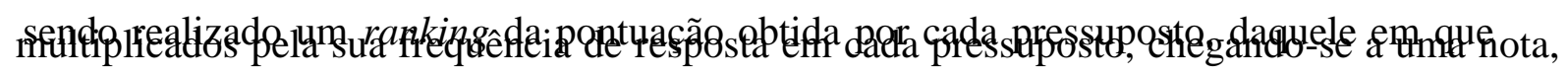
q

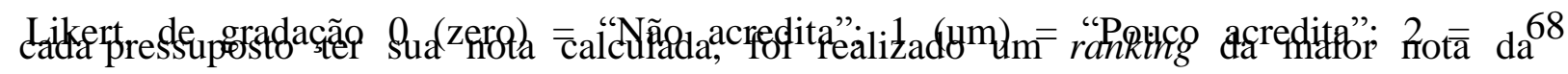
classificação “Acreditam totalmente" para a menor nota. Desta forma, facilita a visualização, entendendo-se que, quanto maior a nota, mais esse pressuposto ainda está arraigado nas práticas docentes do ensino superior atual.

O questionário foi disponibilizado na internet para ser respondido online por meio do programa de coleta de dados online Google Docs. Foi realizado um pré-teste com cinco docentes do ensino superior de direito, que sugeriram algumas mudanças na estrutura das perguntas para melhorar o entendimento. Após isso, o questionário sofreu pequenas alterações, sendo aplicado novamente, desta vez usando uma amostra probabilística de 40 professores do ensino superior de uma Universidade Privada de Fortaleza.

Com a tabulação dos dados, elaborou-se um ranking de quais pressupostos implícitos preconizados por Rogers (1972) que os professores de Direito da Universidade estudada mais acreditam: 
Gráfico 1 - Ranking do que os professores do ensino superior mais acreditam com relação aos pressupostos implícitos de Rogers.

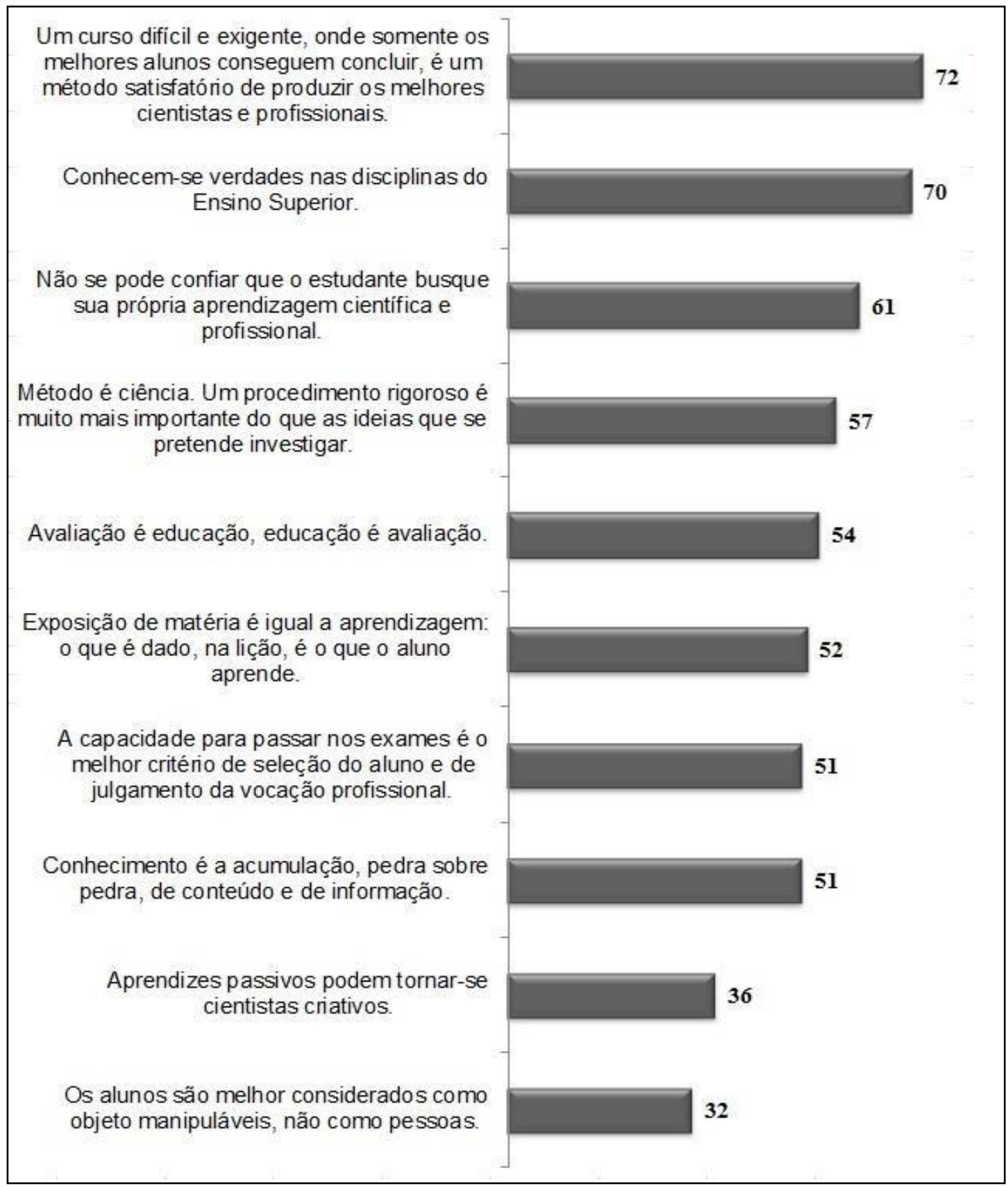

Fonte: Dados da pesquisa em uma Instituição de Ensino Superior Privada de Fortaleza (2014).

Demonstra-se no Gráfico 1 que o pressuposto "um curso difícil e exigente, onde somente os melhores alunos conseguem concluir, é um método satisfatório de produzir os melhores cientistas e profissionais" é o fundamento que mais acreditam. Ocorre que este modo de pensar não está preocupado com o desenvolvimento dos alunos e somente com 
resultados em provas. Conforme Rogers (1972), os alunos que não se adaptam a este sistema são considerados incapazes, este modo de avaliar não baliza a real capacidade dos alunos.

Em segundo lugar, os professores ainda acreditam que "conhecem-se verdades nas disciplinas do ensino superior”. Esse pressuposto aponta o pensamento tradicional do ensino que limita o pensamento crítico, estimulando a mera aceitação do conteúdo passado como verdade universal e não passível de crítica. Segundo esse pensamento, o aprendizado construído por meio das diferenças entre culturas e troca de experiências entre os alunos e o professor e o aluno não é estimulado.

Outro dado que merece atenção é a visão da necessária participação dos alunos no processo de aprendizagem. Entre os professores ouvidos poucos foram os que acreditaram ser possível o desenvolvimento de bons cientistas e pensadores quando estes correspondem a alunos passivos. A capacidade do professor de despertar interesse de seus alunos em participar do processo de ensino também resta evidenciado como elemento fundamental para o alcance do objetivo de uma aprendizagem significativa.

\section{PROGRAMA DE MONITORIA E GRUPOS DE ESTUDO NA EXPERIÊNCIA DE UMA INSTITUIÇÃO DE ENSINO SUPERIOR EM FORTALEZA}

Observando agora a realidade do corpo discente da mesma Instituição pesquisada, bem como das atividades voltadas para o inicio da atividade docente fez-se um estudo junto aos alunos integrantes dos Grupos de Estudo formados e orientados pelo programa de monitoria desta instituição.

Desde o primeiro semestre de 2010, o Curso de Direito da IES em analise tem organizado, juntamente com os monitores voluntários e institucionais, o Grupo de Estudo Dirigido - GED -, que consistem em encontros semanais nas salas de aula do campus da Instituição, mais especificamente nas instalações do curso de Direito, com a orientação dos monitores e a participação dos alunos matriculados nas respectivas disciplinas.

Assim, o estudo em grupo possibilita não só uma melhoria na aprendizagem como também uma melhoria de convívio, de relacionamento entre os alunos que passam a se conhecer mais e interagir com outros colegas e a continuidade no estudo.

Não bastando isso, tendo em vista a diversidade dos membros que atualmente compõem as salas das IES, com idades, formação, cultura e objetivos 
diversos o processo de comunicação do professor com cada público específico de alunos se torna mais complexo, podendo causar distanciamento ou maior dificuldade de compreensão das disciplinas.

No primeiro semestre de 2014, foi realizada uma pesquisa de satisfação com os participantes do GED, foram ouvidos 25 Grupos. Dentre os questionamentos e respostas apresentadas destacam-se os seguintes:

Quesito 01. O que lhe motivou a participar do GED? Nesse quesito $41 \%$ apontaram a dificuldade de aprendizagem e absorção dos conteúdos, seguido de $37 \%$ que afirmaram necessitar de atividades complementares e ainda de $22 \%$ que apontou necessidade de revisar matérias para concursos e Exame de Ordem.

Quesito 02. Você se sentiu mais a vontade para realizar questionamento e tirar eventuais dúvidas com o orientador do GED? Nesse ponto os indicativos são bem mais expressivos, pois $96 \%$ disseram que sim enquanto apenas $4 \%$ afirmaram que não o que demonstra claramente que existe um maior conforto e proximidade entre os integrantes do grupo comparativamente ao professor e o ambiente de sala de aula o que também constitui em contribuição efetiva ao processo de ensino.

Quesito 03. Com o ingresso no GED houve uma melhora no seu rendimento acadêmico? Nesse ponto $83 \%$ dos entrevistados reconheceram que sim, $0 \%$ apontou a resposta negativa, havendo ainda $16 \%$ que indicaram uma melhora parcial seguidos de $1 \%$ que afirmaram que sim, mas não exclusivamente por conta do GED. Nesse ponto, observa que o estudo em Grupo contribui não só no estudo individual, porém na melhora do rendimento como um todo, contribuindo assim para além da disciplina objeto do estudo.

Quesito 04. Você acredita que o GED é uma ferramenta importante no processo de aprendizagem? Quanto a este questionamento 97\% dos alunos reconheceram que sim enquanto $3 \%$ afirmaram ser parcialmente importante contra $0 \%$ de indicação de que não seria importante. Percebe-se que, em uma autoindicação, os alunos se identificam e gostam da utilização da ferramenta, reconhecendo que ela desempenha um papel significativo na compreensão dos conteúdos ministrados no decorrer do curso.

Acredita-se, portanto, que o estudo em grupos oficiais, organizados pela IES e orientados por professores, monitores e pós-graduandos capacitados para esse fim é ferramenta essencial ao aprimoramento do processo de ensino e aprendizagem. 
Além disso, essa realidade pode vir a se coadunar com o levantamento realizado com os docentes da IES no que diz respeito aos pressupostos implícitos de Carl Rogers uma vez que a existência de um programa de monitoria e de Grupos de Estudo estimula a participação do aluno mais ativamente no processo de aprendizagem além de aprimorar a relação entre o corpo discente e docente, favorecendo ainda o despertar da vocação docente entre os alunos do curso.

\section{CONCLUSÃO}

Diante dos aspectos abordados neste trabalho e da análise das obras tomadas por base bem como dos resultados obtidos para sua execução pode-se concluir que a educação é um direito basilar do cidadão e instrumento necessário ao real desenvolvimento do país em todos os aspectos. No entanto, sofre com uma crise crescente e a falta de investimentos sérios e contundentes para o seu desenvolvimento.

O ensino jurídico é de grande importância para a sociedade, primeiro pela formação de profissionais do direito e segundo por conta de sua interdisciplinaridade e tradição de formação, sendo a primeira instituição de ensino superior instituída no Brasil e responsável pelo rompimento com diversos paradigmas ultrapassados.

O ensino jurídico enfrenta uma grave crise que por sua vez se repercute em todo universo do direito, em parte ocasionada pelo enfraquecimento das universidades públicas, falta de seriedade e compromisso das instituições particulares e pela própria crise geral da educação. Além disso, a equivocada tradição dogmática prejudica o ensino e estudo do direito.

O Direito se caracteriza como uma ciência social uma vez que seu ponto de análise são as relações sociais e suas constantes modificações. As normas se destinam a estabelecer um sistema de compartilhamento da liberdade dos cidadãos que vivem em uma sociedade. Diante disso, não há necessidade de ciência jurídica onde não houver. sociedade. Não se podem estabelecer limitações à ciência do Direito como os princípios ou o ordenamento jurídico. O campo de atuação da ciência jurídica é ilimitado, como também o são as relações sociais. 
A chamada dogmática jurídica revela-se um equívoco desde a denominação. Se o dogma é indiscutível, inquestionável, como pode atrelar-se ao conhecimento científico? Dogma se afigura possível, por exemplo, no conhecimento religioso, baseado na crença em existência de divindades que, cientificamente, não se tem prova da existência. Entretanto, o pensamento científico é incompatível com a ideia de dogma, logo a dogmática jurídica é incompatível com a ciência do direito e essa relação entre Direito e dogma ou tentativa de limitação à ciência jurídica deve ser rechaçada.

É necessária uma mudança de paradigma no ensino do direito, uma ruptura com a dogmática e uma busca pelo conhecimento e pela visão crítica do direito. Tal realidade passa diretamente pelos cursos de pós-graduação responsáveis pela formação dos professores de direito. A avaliação crítica passa ainda pela prática docente do professor, que deve centrar-se no "aprender a conhecer" e não apenas no repasse e mera repetição de conteúdos. $\mathrm{O}$ aluno de direito deve, antes de tudo, aprender a pensar, a formular críticas e a produzir novos conhecimentos. O papel do professor é imprescindível nesta competência.

Além da pós-graduação estratégias de desenvolvimento de talentos no campo docente desde a graduação como o programa de monitoria e de métodos de aperfeiçoamento de ensino como a formação de grupos de estudo podem ser eficazes e úteis à formação de uma visão crítica do direito e de melhoria da qualidade do ensino como um todo.

\section{REFERÊNCIAS}

ALMEIDA, M. M. A escassez de líderes no mercado de trabalho: O papel do professor universitário na formação deste profissional pode colaborar para a mudança do cenário atual. Gestão \& Sociedade, Belford Roxo, v. 1, n. 1, jul. 2012

BARBOSA, J. R. A. Didática no ensino superior. 2 ed. Curitiba: IESDE Brasil S.A., 2011.

BRASIL. Conselho Nacional de Educação; Câmara de Educação Superior. Resolução no.: 09 de 09 de setembro de 2004. Institui as Diretrizes Curriculares Nacionais do Curso de Graduação em Direito e dá outras providências. Disponível em: <http://portal.mec.gov.br/cne/arquivos/pdf/rces09_04.pdf>. Acesso em 20 de jul. de 2014.

BOURDIEU, P.; PASSERON, J. C. A reprodução - elementos para uma teoria do sistema educativo. Rio de Janeiro: Editora Francisco Alves, 1975. 
DEMO, P. O Bom Docente. Fortaleza: Universidade de Fortaleza, 2008 (Temas Pedagógicos).

MACHADO SEGUNDO. H. de B. Por que Dogmática Jurídica? Rio de Janeiro: Forense, 2008.

FERREIRA, D. R. M.; SILVA, K. M. A.; SHUVARTZ, M. Ensino superior: As dificuldades da prática docente. In: CONGRESSO DE EDUCAÇÃO DO SUDOESTE GOIANO, 25, Goiânia. Anais... Goiânia: UFG, 2009.

PIMENTA, S. G.; ANASTASIOU, L. das G. C. A docência no ensino superior. São Paulo: Cortez, 2002.

HOLANDA, A. P. A.. A escola do recife e seu papel na construção do ensino jurídico brasileiro: uma ruptura de paradigmas. In: CARLINI, Angélica; CERQUEIRA, Daniel Torres de; ALMEIDA FILHO, José Carlos de Araújo (Orgs.). 180 anos do ensino jurídico no Brasil. São Paulo: Millennium, 2007.

MACHADO SEGUNDO. Hugo de Brito. Por que Dogmática Jurídica? Rio de Janeiro: Forense, 2008.

MILANESI, P. V. B.; AMATUZZI, M. M. Os sentidos da liberdade segundo professores da educação básica. Psicologia da Educação, São Paulo, n. 27, p. 115-139, $2^{\circ}$ sem. de 2008.

MINAYO, M. de S. (Org.) Pesquisa Social: Teoria, método e criatividade. 23 ed. Petrópolis: Vozes, 2004.

POMPEU, Gina Vidal Marcilio. Direito à Educação: controle social da exigibilidade judicial. São Paulo: ABC editora, 2005.

RODAS, J. G. A Universidade e as novas tecnologias. In: $<$ http://posgraduando.com/blog/a-universidade-e-as-novastecnologias?utm_source=feedburner\&utm_medium=email\&utm_campaign=Feed $\% 3 \mathrm{~A} \%$ 20posgraduando\%20\%28PosGraduando\%29.>. Acesso em 19 de amrço de 2015.

ROGERS, C. Pressupostos correntes sobre educação universitária: Uma exposição apaixonada. In: Liberdade para aprender (pp. 163-180). Belo Horizonte, Minas Gerais, Brasil: Interlivros, 1972

SObREIRA, M. C.; BARBosA, A. M.; AlmEIDA, A. O. G.; FORTE, S. H. A. C. Pressupostos Implícitos de Rogers: Uma Análise sobre o Contexto Atual da Educação Superior. In: BUGARIM, C.; TASSIGNY, M.. (Org.). Coletânea didática no ensino superior I: Didática e casos de ensino. .1ed.Fortaleza: Editora Universidade de Fortaleza, 2014, v. 1, p. 221-238.

TARDIF, M.; LESSARD, C. O Ofício de Professor: história, perspectivas e desafios internacionais. Trad. Lucy Magalhães. 4. Ed. Petrópolis, RJ: Vozes, 2011 
WARAT, Luis Alberto. Epistemologia e ensino jurídico: o sonho acabou. Florianópolis: Fundação Boiteux, 2004.

ZIMRING, F. Carl Rogers. Recife: Fundação Joaquim Nabuco, Editora Massangana, 2010. 